\title{
CALCULATION OF THE HEAT EXCHANGE PROCESS FOR GEOMETRIC PARAMETERS
}

\author{
Nodir Turakhodjaev ${ }^{1}$, Mukhammadali Akramov ${ }^{2}$, Shirinkhon Turakhujaeva ${ }^{3}$, Sarvar Tursunbaev ${ }^{1}$, Azizakhon \\ Turakhujaeva ${ }^{1}$, Jamaliddin Kamalov ${ }^{4}$ \\ ${ }^{1}$ The Tashkent State Technical University, Uzbekistan. \\ ${ }^{2}$ Ferghana Polytechnic Institute,Uzbekistan. \\ ${ }^{3}$ Turin Polytechnic University in Tashkent,Uzbekistan. \\ ${ }^{4}$ UZBEK-JAPAN Innovation Center of Youth ${ }_{2}$ Uzbekistan. \\ Email: red engineer94@mail.ru
}

\begin{abstract}
In the article, results of researches on mathematical process modeling of heating and flow of a blend are given in the gas mine furnace for the melting of aluminum alloys. By the results of the calculation of mathematical modeling, geometrical parameters of the gas-melting furnace for experimental studies were changed and samples of melting trunks are received. Contrastive analysis of results of melting in the existing furnace and the furnace with optimization of geometrical parameters showed advantages of mathematical modeling of technology of melting and selection of the heating mode of a blend before loading in the furnace.
\end{abstract}

Keywords: Mathematical Model, Heat Exchange, Loading In The Furnace, Fusion, Coefficient, Heat Conductivity, Energy-Saving, Construction.

\section{Introduction}

Effective calculation of all production cycle is reached application of a mathematical model. In foundry production, the mathematical model is applied to the calculation of the heat-exchanging process, to the optimization of the melting modes and filling, the fusion processing modes, etc. One of the main objectives for receiving quality fusion is the preparation of a blend for loading in the melting furnace. The mathematical model which allows to optimize in a compressed interval of time a standby mode [1-3] is also applied to the calculation of a blend. In new software developments of optimization of design data of melting units, mathematical modeling of the heat-exchanging process allows the reduction of the time for optimization of parameters due to the reduction of the number of experimental studies. Besides process modeling allows to lower capital expenditure for carrying out experiments, provides resource-saving and energy-saving, and also provides a decrease in harmful effects on the environment [4]

\section{Related Work}

Research and development work was carried out in gas furnaces for melting shaft-type aluminum alloys. The furnace was charged with a charge of various chemical compositions at various temperature conditions. Sampling was carried out in a copper chill mold [5]. The temperature characteristics were determined with an optical pyrometer. Phase identification was carried out using a scanning electron microscope SEM-Zeiss EVO MA 10 (Carl Zeiss) (fig 1.) and an intelligent diffractometer (Empyrean Malvern Panalytical). The analysis of alloys was carried out using an optical spectroscopy UV-VIS-NIR [6-9].

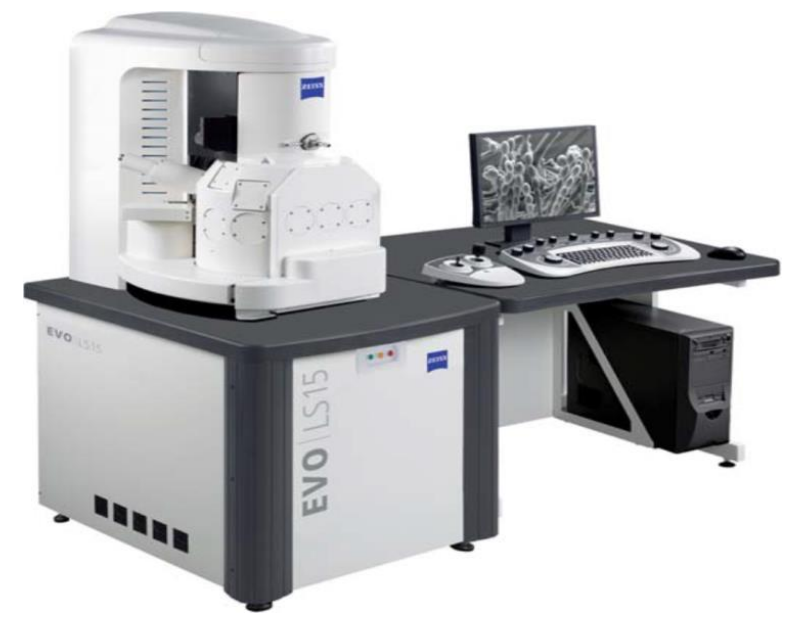

Fig. 1. Electron microscope

The mathematical model of calculation of a blend for receiving cast metal composites is described by a condition of their full melting [10]:

$$
x\left(\tau_{2}\right)=l
$$


In the system of flow of a blend in a liquid bathtub process two-phase: a firm blend - liquid fusion. Fourier's equation, initial and boundary conditions register in a look

$$
\begin{aligned}
& \frac{\partial T_{1}^{\prime}}{\partial \tau}=\frac{a_{1}}{x^{2}} \frac{\partial}{\partial x}\left(x^{2} \frac{\partial T_{1}^{\prime}}{\partial x}\right) \\
& T_{1}^{\prime}\left(\tau_{1}, x\right)=F_{2}(x) ; \quad \frac{\partial T_{1}^{\prime}}{\partial x}(\tau, 0)=0 \\
& \lambda_{1} \frac{\partial T_{1}^{\prime}}{\partial x}(\tau, l)=\alpha\left[T_{M}^{\prime \prime}-T_{1}^{\prime}(\tau, l)\right]
\end{aligned}
$$

The end of a stage of blend melting comes when the blend completely melts at

$$
x\left(\tau_{3}\right)=0
$$

These systems of equations describing the process of melting the charge at different stages have no analytical solution and are solved by numerical methods. In this case, the main is the integral characteristic of the process, that is, the time of melting of the charge. Therefore, for the solution, we apply an integral method based on the choice for the temperature distribution in a piece of charge, a metal crust, and a liquid metal in a spherical shape. We find the values of the constants from the conditions that satisfy the boundary and balance conditions. In our case, that is, with a quasi-stationary approximation for a conventionally accepted spherical piece of charge according to the data of [11], the temperature distribution has the following form:

$$
T(x, \tau)=T_{u}+\frac{T n-T u}{R}\left(1-\frac{R}{x}\right) R,
$$

where Тц - temperature of a middle part of a blend, ${ }^{0} \mathrm{C}$;

Tn - blend surface temperature, ${ }^{\circ} \mathrm{C}$;

$R$ - the accepted estimated radius of a blend, $\mathrm{m}$.

Taking into account boundary conditions when the piece of a blend in the melting camera is not mobile, and the blend represents a thermally thin body, the value of the coefficient of a convective heat transfer is determined by criteria formulas [12]

$$
\begin{gathered}
\alpha=\frac{\lambda \cdot N u}{\beta} ; \quad N u=A\left(\frac{G r \cdot \operatorname{Pr}^{2}}{1+\operatorname{Pr}}\right)^{m} \\
G r=\frac{g \cdot v\left(T_{M}^{\prime \prime}-T_{u}\right) \cdot \beta}{v^{2}} ; \operatorname{Pr}=\frac{v}{a},
\end{gathered}
$$

where $\mathrm{A}$ and $\mathrm{m}$ - the constants determined by the nature of a blend;
According to the studies carried out, the value of the coefficient A was taken, which is 0.6 , with $\mathrm{m}=$ 0.25 . Taking into account the accepted values, we obtain a system of linear differential equations calculated with respect to the time of melting of the charge.

$$
H_{K P} \geq \frac{G \cdot \tau}{\rho \cdot F u} \approx 0,15 m
$$

The heat exchange process is described by the heat balance equation for heating the charge [13]

$$
Q_{\text {npux }}^{\prime}=Q_{p a c x}^{\prime}
$$

The total amount of heat input into the overheating chamber will be as following

$$
Q_{n \text { nиx }}^{\prime}=Q_{X}+Q_{\theta}+Q_{2}+Q_{\phi}+\tilde{O}^{\prime}
$$

where $\mathrm{Qx}$ - the chemical warmth of gas burning;

$\mathrm{Q}_{\mathrm{B}}$ - the physical warmth entered by air;

$Q_{\Gamma}$ - the physical warmth entered by gas;

$\mathrm{Q}_{\phi}$ - the physical warmth entered by metal from the melting camera;

Ớ - physical warmly entered by an electric arc.

The chemical warmth of gas burning is equal

$$
Q_{x}=Q_{H}^{P} \cdot \beta_{0}
$$

where

$Q^{P} H^{-}$a net calorific value of gas, $\mathrm{J} / \mathrm{m}^{3}$;

$\boldsymbol{\beta}_{0}$ - gas consumption, $\mathrm{m}^{3} / \mathrm{s}$;

The physical heat introduced by air is equal to

$$
Q_{\text {s }}=\beta_{0} \alpha_{l} i_{\beta}
$$

Thus, the formula will take the following for

$$
Q_{\text {B }}=\beta_{0} \cdot \alpha_{l} \cdot T_{\text {в }} \cdot 1,3
$$

So, the physical heat introduced by the gas is determined by the formula

$$
Q_{r}=\beta_{0} \cdot C_{0}^{t} \cdot T_{T}
$$

where

$C^{t} 0$ - average heat capacity of gas, $\mathrm{J} / \mathrm{m}^{3} \bullet \mathrm{K}$; $T_{T^{-}}$gas temperature, $\mathrm{K}$.

According to the data, we derive the average heat capacity of the gas depending on the temperature

$$
C_{o}^{t}=1,540+1,1 T_{T}
$$

The physical heat introduced by the metal from the melting chamber is determined by the formula [14] 


$$
Q_{\phi}=G \cdot i_{M}^{\prime \prime}
$$

where

$G$ - furnace performance, $\mathrm{kg} / \mathrm{s}$

$i_{M}$ - enthalpy of liquid aluminum, $\mathrm{J} / \mathrm{kg}$, which is determined by the formula

$$
i_{M}^{\prime \prime}=280,700+1,028 T_{M}^{\prime \prime}
$$

Thus, the arrival of heat into the overheating chamber is

$$
\begin{aligned}
& Q_{\text {npux }}^{\prime \prime}=Q_{H}^{P} \beta_{0}+\beta_{0} \alpha_{1} T_{\sigma} \cdot 1,3+\beta_{0} T_{T}\left(1,540+1,1 T_{T}\right) \\
& +G\left(280,700+1,028 \cdot T_{M}^{\prime \prime}\right)
\end{aligned}
$$

The heat consumption entering the overheating chamber has the following 6 components:

The loss of heat with leaving combustion products, which is determined by the formula

$$
Q_{1}=\beta_{0} V_{y}^{\prime} C^{\prime} T_{y}^{\prime},
$$

where - a volume of exhaust combustion products per unit of gas, $\mathrm{m}^{3} / \mathrm{m}^{3}$, which, taking into account the coefficient of thermal expansion, is determined by the formula

$$
V_{y}^{\prime}=10,5+0,0038 T_{y}^{\prime}
$$

$V_{y}$ - heat capacity of combustion products, $\mathrm{J} /\left(\mathrm{m}^{3} \cdot \mathrm{K}\right)$.

From sources [15], the heat capacity of combustion products has the following dependence on temperature:

$$
C_{y}^{\prime}=1,369+0,24 T^{\prime}
$$

where $T$ - flue gas temperature, $\mathrm{K}$.

We accept the temperature distribution of combustion projects along the length of the furnace as linear:

$$
T_{y}=T_{r}-1445 \cdot \beta,
$$

where $\mathrm{Tr}$ - gas combustion temperature, $\mathrm{K}$;

Heat loss due to the thermal conductivity of the walls of the overheating chamber, free of liquid melt

$$
Q_{2}=\frac{T_{C P}^{\prime}-T_{0}}{\frac{1}{\alpha_{1} F_{1}}+\frac{S_{1}}{\lambda_{1} F_{1}}+\frac{S_{2}}{\lambda_{2} F_{2}}+\frac{S_{3}}{\lambda_{3} F_{3}}+\frac{1}{\alpha_{2} F_{4}}}
$$

where - average temperature of combustion products in the overheating chamber, $\mathrm{K}$, equal

$$
T_{C P}^{\prime}=\frac{T_{r}-T_{y}^{\prime}}{2} ;
$$

$T_{C P}$ - ambient temperature, $\mathrm{K}$;
Heat transfer coefficient from combustion products to masonry and from metal to masonry, $\left.\mathrm{Vt} / \mathrm{m}^{2} \bullet \mathrm{K}\right)$, which is defined by the following formula

$$
\begin{aligned}
& \alpha_{1}=\frac{4,96 E M\left[\left(\frac{T_{M}^{\prime}}{100}\right)^{4}-\left(\frac{T_{k}}{100}\right)^{4}\right]}{T_{M}^{\prime}-T_{k}}+ \\
& + \\
& 4,96 \operatorname{Er}\left[\left(\frac{T_{C P}^{\prime}}{100}\right)^{4}-\left(\frac{T_{k}}{100}\right)^{4}\right],
\end{aligned}
$$

where in Eм - blackness of liquid material;

Er - flue gas blackness;

Тк - flue gas blackness, $\mathrm{K}$;

$\mathrm{F}$ - area of the surface of the masonry free from the liquid melt, $\mathrm{M}^{2}$, is defined by the formula

$$
F_{1}=\left(A+2 \beta_{1}\right)\left(H_{0}-H\right)+A \cdot \beta_{1}
$$

where in $\mathrm{H}_{0}$ - the height of the reflective part of the oven, $\mathrm{m}$; $\mathrm{H}$ - melt level, $\mathrm{m}$.

Height of a reflective part of the furnace is equal to the sum of height level of fusion $\mathrm{H}$ and height of a free space over fusion $\mathrm{Hc}$ :

$$
H_{0}=H+H_{C}
$$

The height of a free space of $\mathrm{H}$ is defined proceeding from the value of the slopes influencing heat exchange by radiation

\section{Method}

As shown in researches in the field of heatexchanging processes, when calculating heat exchange by radiation between two surfaces, each of which has certain final sizes, determination of the numerical value of slopes in many cases represents a very difficult task. For the melting furnace with heating slope of radiation from $F_{1}$ laying surface to a metal mirror surface in cameras of melting and overheating of $\mathrm{F}_{2}=\mathrm{F}_{\text {кпр }}+\mathrm{F}_{\text {кпл }}$ can be found in a general view by double integration [16]

$$
\lambda_{1,2}=\frac{1}{F_{2}} \int_{F_{1}} \int_{F_{2}} \frac{\cos \lambda_{1} \cdot \cos \lambda_{2}}{\pi z^{2}} d F_{1} d F_{2}
$$

However, calculating the numerical value of the double integral using this formula is difficult even with simple geometric shapes of both surfaces.

The calculation formulas for the slopes obtained by double integration according to this formula are not suitable for use in practice. The slope value is determined by the angles of the location of both surfaces in space [17]. 
In a smelting furnace with a rectangular bath, the heat-absorbing surface is a metal mirror in the overheating and melting chambers:

$$
F_{M}=F_{\kappa n p}+F_{\kappa n л}=A\left(\beta_{1}+\beta_{2}\right)
$$

Radiation area is the general laying of $\mathrm{F}_{\mathrm{ob}}$ of the arch of the furnace and the side walls having a height of a free space over $\mathrm{H}_{c}$ :

$$
F_{\text {об }}=A \cdot \beta_{1}+2 H_{C} \cdot \beta_{1}+H_{C} \cdot A
$$

Hence, the slope for the parallelepiped will be

$$
\lambda=\frac{F_{M}}{F_{\text {об }}}=\frac{A \cdot \beta_{1}}{A \beta_{1}+2 H_{C} \beta_{1}+H_{C} A}
$$

Therefore, the height of the free space

$$
H_{C}=\frac{A \beta_{1}(1-\lambda)}{\lambda\left(2 \beta_{1}+A\right)}
$$

To determine the optimal value, we set it in the range from 0 to 10 with a step of 0.1 and calculate for each value the total free space area of the reflective part of the melting furnace,

$$
F_{\text {об }}=\frac{F_{M}}{\lambda}
$$

The thermal conductivity of the lining, $\mathrm{W} /(\mathrm{m} \bullet \mathrm{K})$ for the refractory is determined by the following formula

$$
\lambda_{1}=0,84+0,00058 T_{K}
$$

The thermal conductivity coefficient of the insulating layer, $\mathrm{W} /(\mathrm{m} \bullet \mathrm{K})$, for asbestos cardboard, is determined by the following formula

$$
\lambda_{1}=0,157+0,000014 T_{H}
$$

where:

$\mathrm{TH}$ - temperature of an insulating layer, $\mathrm{K}$.

Surface area of an insulating layer, $\mathrm{m}^{2}$,

$$
F_{2}=\left(H_{0}-H+S_{1}\right)\left(A+4 S_{1}+2 \beta_{1}\right)
$$

Coefficient of heat emission of a casing, W / $\left(\mathrm{m}^{2} \bullet\right.$ J) is defined by a formula

$$
\alpha_{2}=\frac{4,96 E c\left[\left(\frac{T c}{100}\right)^{4}-\left(\frac{T_{0}}{100}\right)^{4}\right]}{T c-T_{0}},
$$

\section{Result}

In a mathematical model, both the filling ability of a bathtub and all heat physical coefficients of the melting of aluminum alloys in gas furnaces allowed to consider the application of the above-stated data.
For determination of calculation efficiency of geometrical parameters of the melting gas furnace carried out the comparative analysis of models of the received castings.

In figure 2 and 4 results of swimming trunks are given in gas mine furnaces with optimization of overall dimensions of a bathtub and the mine of the furnace. In the drawing 1 structure of the aluminum alloy received from the mine gas furnace before optimization of overall dimensions.

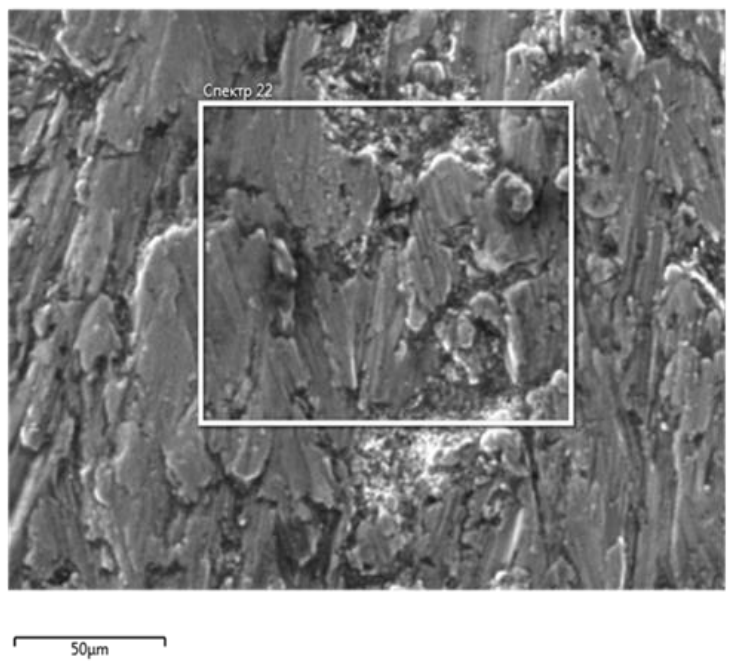

Figure 2. Structure of aluminum alloy from the furnace before optimization of overall dimensions

Table 1

\begin{tabular}{|c|c|c|}
\hline Element & Weight.\% & Sigma Weight.\% \\
\hline $\mathrm{C}$ & 16.73 & 0.54 \\
\hline $\mathrm{O}$ & 8.51 & 0.21 \\
\hline $\mathrm{Al}$ & 64.29 & 0.46 \\
\hline $\mathrm{Si}$ & 9.25 & 0.14 \\
\hline $\mathrm{Cu}$ & 1.22 & 0.14 \\
\hline Sum: & 100.00 & \\
\hline
\end{tabular}

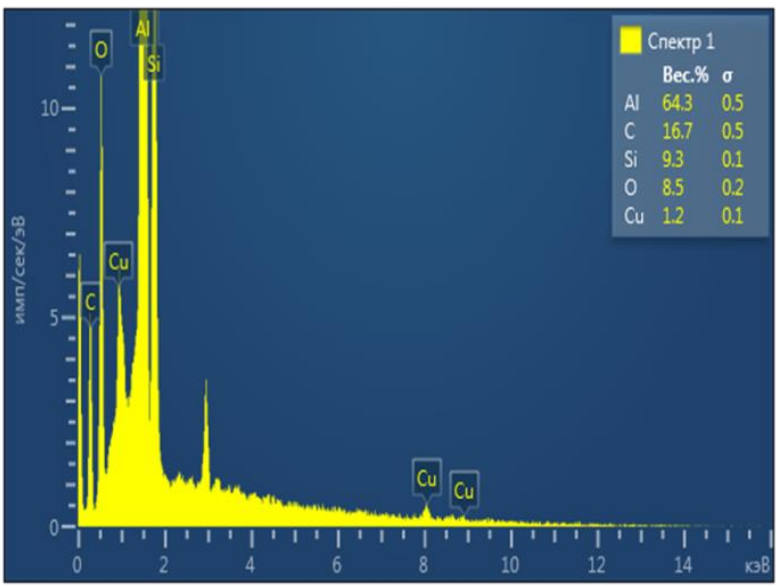

Fig. 3. Indicators of chemical composition of aluminum alloy 


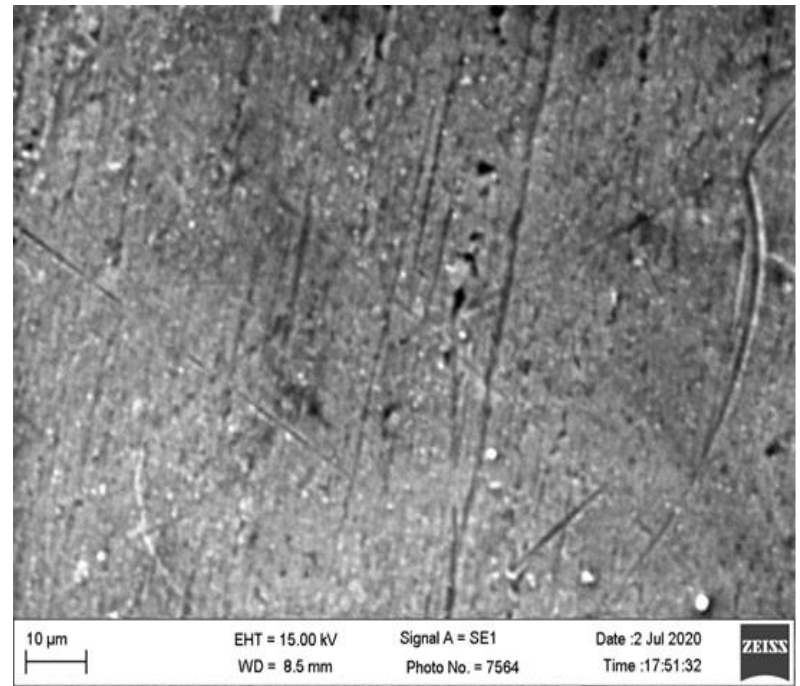

Figure 4. Structure of aluminum alloy from the furnace before optimization of dimensional sizes.

Table 2.

\begin{tabular}{|c|c|c|}
\hline Element & Weight. \% & Sigma Weight .\% \\
\hline $\mathrm{O}$ & 7.31 & 0.41 \\
\hline $\mathrm{Na}$ & 0.49 & 0.13 \\
\hline $\mathrm{Al}$ & 81.35 & 0.64 \\
\hline $\mathrm{Si}$ & 2.78 & 0.20 \\
\hline $\mathrm{Cl}$ & 0.56 & 0.12 \\
\hline $\mathrm{K}$ & 0.39 & 0.12 \\
\hline $\mathrm{Cr}$ & 2.51 & 0.27 \\
\hline $\mathrm{Fe}$ & 3.10 & 0.34 \\
\hline $\mathrm{Cu}$ & 1.51 & 0.35 \\
\hline $\mathrm{Sum}:$ & 100.00 & \\
\hline
\end{tabular}

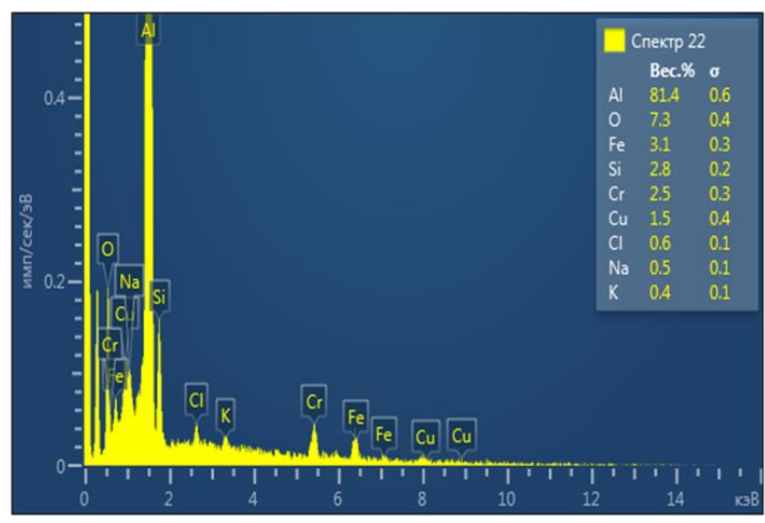

Fig. 5. Indicators of chemical composition of aluminum alloy

\section{Conclusions}

Thus, according to the results of calculating the geometric parameters of the furnace, the preparation mode of the charge and the technology for melting aluminum alloys, it is possible to achieve good results not only in terms of economic indicators but also in terms of the quality of the resulting alloy.

\section{References}

[1] Grachev V.A., Turakhodjaev N.D., Influence of High-Temperature Treatment of Melt on the Composition and Structure of Aluminum Alloy//Archives of foundry Engineering DOI: 10.1515/afe-2017-0131,pp.61-66.

[2] Vladimir Grachev., Nodir Turakhodjaev., Influence Of Liquid Aluminum Alloy Treatment At Temperatures Up To $2000^{\circ} \mathrm{C}$ In Terms Of The Alloy Structure And Gas Aluminum Oxides Content//International Journal of Mechanical Engineering and Technology (IJMET) Volume 9, Issue 7, July 2018, pp. 489-495.

[3] Nodir Turakhodjaev, Sarvar Tursunbaev ,Sherzod Tashbulatov, Munira Kuchkorova "Analysis of technological solutions for reducing the copper concentration in slags from oxygenflare smelting of copper sulfide concentrates" Journal of Critical Reviews ISSN- 2394-5125 Volume 7 , Issue 5, 2020 y http://dx.doi.org/10.31838/icr.07.05.95

[4] Turakhodjaev Nodir, Tashbulatov Sherzod, Zokirov Ruslan, Tursunbaev Sarvar, Baydullaev Azamat "Studying the scientific and technological bases for the processing of dumping copper and aluminum slags" Journal of Critical Reviews ISSN- 2394-5125 Volume 7, Issue $11,2020 \quad \mathrm{y} \quad$ DOI: http://dx.doi.org/10.31838/icr.07.11.79

[5] Sherzod B.Tashbulatov, Nodir D. Turahadjaev, Kudratkhon G. Bakhadirov. ProcedureTechnique for New Type Plasma Chemical Reactor Thermo-physical Calculations. American Journal of Materials Engineering and Technology Vol. 3, No. 3, 2015, pp. 58-62.

[6] Turakhodjaev Nodir, Chorshanbiev Shukhrat, Sadikova Nargiza,Chorshanbiev Kulmukhammad "Ways to increase the strength of of shaftgear teeth working in a highly abrasive grinding environment" Journal of Critical Reviews ISSN- 2394-5125 Volume 7, Issue $7, \quad 2020 \quad \mathrm{y}$. http://dx.doi.org/10.31838/jcr.07.07.163

[7] Yang Wang, Feng Zhong, Ruizhi Wu, Huajie Wu,Nodir Turakhodjaev, Bakhadirov Kudratkhon, Jianfeng Sun, Legan Hou,Jinghuai Zhang, Xinlin Li,Milin Zhang "High-strength, ductility and modulus $\mathrm{Al}-\mathrm{Li} / \mathrm{B}_{4} \mathrm{C}$ composite with near nanostructure produced by accumulative roll bonding" Journal of Alloys and Compounds Volume 834,5 September 2020, 155105

[8] Turakhodjaeva F.N., Turakhodjaev N.D., Chorshanbiev Sh.M., Tashbulatov Sh.B., Nazarova N.T. The process of developing a technology for extracting copper and other nonferrous metals from industrial slags //Corporate Governance: Theory and Practice. Collection of scientific papers on 23.01.2019, P. 363-364 
[9] Turakhodjaeva F.N., Turakhodjaev N.D. Application of bio-cement as an environmentally friendly building material // Modern ecological state of the environment and scientific and practical aspects of environmental management. IV International Scientific and Practical Internet Conference, Russia, Astrakhan Region 02/28/2019 P.68-71.

[10] Nodir D.Turakhodjaev, Shirinkhon N.Turakjodjaeva, Jamaliddin S.Kamalov. The process of melting aluminum alloys to improve the quality of castings// Processing and Fabrication of Advanced Materials XXVII International Conference, Jonkoping, Sweden 27-29/05/2019 P. 351-354.

[11] Turakhodzhaev N. D., Abdurakhmanov H. Z., Tursunov T. H., Yakubov L. E. Mathematical model of the heat exchange process in a gas furnace. // Collection of scientific articles of the International scientific and practical conference "Modern high-tech technologies: development priorities and training". - Naberezhnye Chelny, 2014. - Pp. 84-89.

[12] Sherzod B.Tashbulatov, Nodir D. Turahadjaev, Kudratkhon G. Bakhadirov. ProcedureTechnique for New Type Plasma Chemical Reactor Thermo-physical Calculations. American Journal of Materials Engineering and Technology Vol. 3, No. 3, 2015, pp. 58-62.

[13] Sherzod Tashbulatov, Lazizkhan Yakubov, Khusniddin Abdurakhmanov, Tokhir Tursunov. Development of New Structural Materials with Improved Mechanical Properties and High Quality of Structures through New Methods. Journal of Materials Science Research, Canadian Center of Science and Education. Vol.5, 2016. № 3. - pp. 52-58.
[14] Turahodjaev N. D., Tashbulatov S. B. the Use of high temperature treatment for recovery of metals from slags. // Composite material. Tashkent, 2015. - No. 1. - pp. 65-67.

[15] V. A. Grachev, N. D. Turakhodjaev, Sh. B. Tashbulatov Improving the quality of aluminum and copper alloys obtained from waste products by high-temperature processing of the melt. Foundry of Russia / / No. 2, 2017 / / pp. 108-119.

[16] V. A. Grachev (Institute of physical chemistry and electrochemistry. A. N. Frumkina RAS), N. D. Turahodjaev, Sh. B. Tashbulatov (Tashkent state technical University, Tashkent, Uzbekistan). Development of flux composition and melting mode of production wastes and slags under flux. Foundry of Russia / / No. 9, 2016 / / pp. 212-221.

[17] Turahodjaev N. D., Tashbulatov Sh. B. the Use of high temperature treatment for recovery of metals from slags. // Composite materials. Tashkent, 2015. - No. 1. - pp. 65-67

[18] Wang Y, Zhang S, Wu R, Turakhodjaev N,Zhang L Liu M, Mardonakulov S "Concurrently improving uniform elongation and strength of ultrafine-grained Al-2Li alloy" Materials Science and Engineering A (2020) 792 DOI: $\underline{10.1016 / \text { i.msea.2020.139848 }}$

[19] Wang D, Wu H,Wu R,Wang Y, Zhang I, Betsofen $\underline{S}, \underline{\text { Krit B }} \underline{\text { Hou L }} \underline{\text { Nodir T "The transformation }}$ of LPSO type in Mg-4Y-2Er-2Zn-0.6Zr and its response to the mechanical properties and damping capacities" Journal of Magnesium and Alloys (2020) DOI: $10.1016 /$ j.jma.2019.10.003 